and the following extract from the Agricultural Gazette of New South. Wales (August 2) is of interest:- "The Chief Quarantine Officer for Plants has informed the Under-Secretary for Agriculture of a most extraordinary method whereby an objectionable weed might be broadcasted throughout the State. It appears that, as an advertising medium, some printed paper, representative of a flying insect, has been sent to Australia, and the genius who invented this particular style of advertisement, in an endeavour to make it more realistic or uncommon, had attached to each specimen the burr or seed of the noxious weed 'Burdock' (Arctium Lappa). The authorities in Western Australia had called the attention of the Director of Quarantine to the use to which the burr of this noxious weed was being put. It is needless to say that business firms stopped the issue of the advertisement under notice as soon as they knew there was a serious objection to its use."

Burdock is a very troublesome weed, and it is clear that our colonial friends have to be on the alert if they are to prevent the introduction of new plants in the manner outlined.

\section{THE LANCASHIRE SEA-FISHERIES} LABORATORY.

THE eighteenth report of the Lancashire Sea-Fisheries Laboratory (for the year 1909) contains an account of work carried cut at the University of Liverpool, at the sea-fish hatchery at Piel, and at the Port Erin Biological Station. Mr. James Johnstone describes five species of internal parasites of fishes from the Irish Sea, the three genera discussed being Lebouria, Prosthecobothrium, and Echeneibothrium. The same author reports on the measurements of some 55,000 plaice from the district, curves representing the frequency of fish at each unit of length for the most important fishing grounds being given. The average weights of plaice at each unit of length from various fishing grounds have also been determined. Taking Heincke's formula $w=\frac{l^{3}}{100} k$ where $w$ is the weight in grams and $l$ the length in centimetres, the monthly variations in the value of $k$ have been calculated for several of the grounds. The value shows a maximum in July, and the minimum appears to be in January, at which time of the year very little food is found in the stomachs of the plaice.

A considerable section of the report is occupied by papers on hydrographical work done in the Irish Sca by Mr. Johnstone and Dr. H. Bassett. It is doubtful, however, whether the comparatively slender data contained in the papers of the latter writer can be usefully employed in the way suggested by him, in connection with the prediction of climatic conditions over extended periods of time. Very much more research will be necessary before such predictions can have any but a speculative value.

The report concludes with a paper by Prof. Herdman, $\mathrm{Mr}$. A. Scott, and Mr. Dakin on plankton work carried out off the Isle of Man in Igog. The paper as a whole tends to confirm the doubts, which have often bcen expressed, as to the value of the quantitative methods of plankton work, as at present practised. Until some trustworthy instrument has been devised for accurately measuring the quantity of water which has passed through the net on each occasion, the elaborate methods of counting the organisms captured would hardly seem to repay the time which must necessarily be employed upon them.

\section{ZOOLOGY AT THE BRITISH ASSOCIATION.}

THE attendance of zoologists at the meetings of Section $D$ was affected by the fact that the International Congress of Zoology at Graz and the International Congress of Entomology at Brussels had taken place so recently. These meetings abroad were probably responsible for the absence of a few of those who in previous years have contributed papers to the section. The programme, being a little less crowded than usual, was taken at a more comfortable pace, and reasonable time was available for discussion and remarks on the various subjects under consideration. The attendance at the meetings of the section was very satisfactory, especially in the circumstances, and the interest in the proceedings was fully maintained to the end; indeed, the concluding meeting was one of the best of the series.

\section{Coral Snakes and Peacocks.}

The popular lecture, which for several years has been a feature of the programme of the section, was given before a large audience by Dr. H. F. Gadow, F.R.S., who chose for his subject "Coral Snakes and Peacocks," and illustrated his remarks by a series of lantern-slides in colour. He first described some of the physical features of Mexico, during a visit to which country his observations on coral snakes (Elaps) were made. The red, black, and yellow markings of these snakes have been said to be of the nature of "warning coloration," but Dr. Gadow pointed out that, although the markings are conspicuous when the snakes are lying in a dish or other vessel, the colours commingle, especially in the dusk, with the natural surroundings of the animal, so that it becomes very inconspicuous. Coral snakes are entirely nocturnal in habit; they lie in hiding during the day, so that the explanation of their coloration as "warning" is unwarrantable. Many harmless snakes are coloured in a similar manner to the coral snakes, e.g. among a large collection of Coronella from various places in Mexico examples of one species were found which seem to have " mimicked" several of the colour patterns exhibited by species of Elaps. But Dr. Gadow pointed out that the specimens of Elaps and Coronella found in the same locality do not exhibit the same colour pattern. Dr. Gadow's conclusion, stated briefly, was that the resemblances in colour pattern between Coronella and Elaps are instances of pseudo-mimicry. In the second part of his address Dr. Gadow traced the gradual transition from a comparatively simple feather with light and dark bands to the "eyed" feather, with fully developed metallic lustre, of the mature peacock's "fan." He then described the retrogressive changes leading from the "eyed " feathers to the modified feathers of the back and margin of the "fan."

\section{Coccidia and Coccidiosis in Birds.}

Dr. H. B. Fantham described his observations on the life cycle of the sporozoon Eimeria (Coccidium) avium, which produces a form of "enteritis" in grouse, fowls, and pheasants, especially in young birds. Resistant oöcysts of the parasite are voided in the fæces of the infected birds, and are acquired by other birds in their food or drink. A mature oöcyst contains four sporocysts, in each of which are two active motile sporozoites. After the oöcysts have been swallowed by a bird, the cyst wall is softened by the pancreatic juice, the sporozoites creep out and penetrate the epithelial cells of the duodenum, in which they become rounded and grow, feeding passively on the host cell. After attaining a certain size, the nucleus and protoplasm of the parasite-now a schizontdivides into a cluster of merozoites arranged en barillet, i.e. like the segments of an orange. Very little residual protoplasm remains after the formation of merozoites. These small, vermicular merozoites glide away and invade other cells, within which they grow to schizonts and multiply. A number of generations of merozoites is produced in this way, and the destruction of the epithelium and the derangements resulting therefrom in some cases cause death of the host. In most instances some merozoites pass down into the cæca, where they grow and multiply, producing intense inflammation. Sooner or later a limit is reached, both to the power of the bird to provide nourishment for the parasites and to the multiplicative capacity of the parasite itself, and then sexual forms are produced. Some of the organisms become large and contain much reserve food material. These are the macrogametocytes, each of which, after the maturation changes, becomes a single macrogamete. Slightly smaller parasites, with little or no reserve material, undergo nuclear multiplication and give rise to many minute biflagellate microgametes, which disperse and swim away in search of macrogametes. Each of the latter has precociously invested itself with a cyst wall, in which a micropyle is

NO. 2 I 39, VOL. 84] 